\title{
Necrotizing Enterocolitis Presented at birth in a Full-Term Baby Born to a Mother with Chorioamnionitis
}

Husam Salama MD, Alaa Al.fakharani MD, Salem K Mammoo

\begin{abstract}
:
Necrotizing enterocolitis of newborn infants is an inflammatory disease affecting most commonly newborn infants born prematurely. This condition's main cause is yet unknown, but immature mucosa associated with the fast introduction of milk are the two major risk pillars. The optimum time of occurrence is between the two weeks of life, and week six depends on the gestation age. It is seldom to occur in full-term newborns and quite unusual to present at birth. The authors present a case where a full-term baby is born with evidence of necrotizing enterocolitis to a mother with chorioamnionitis and antiphospholipid syndrome.
\end{abstract}

\section{Abbreviation:}

aPL: Anti-phospholipid syndrome

CRP: C- reactive protein

FTN: Full-term newborn

NEC: Necrotizing enterocolitis

NICU: Neonatal intensive care

PI: Pneumatosis intestinalis

WBC: white blood cells

Keywords: chorioamnionitis, full-term newborn, NEC, maternal infection, pneumatosis intestinalis, Necrotizing enterocolitis

\section{Case:}

A 39 weeks gestation baby boy born by vacuum vaginal delivery. Mother is a gravida 3 para 0 with two previous abortions. Mother is on a regular subcutaneous low molecular weight heparin and oral aspirin as she has antiphospholipid syndrome. Mother was admitted two days before delivery with abdominal pain, abdominal wall tenderness, vomiting, nausea, tachycardia more than 100 beats/ minute, high-grade fever as well as burning micturition. There was no prolonged rupture of the membrane. The mother's C-reactive protein was 69 , and her WBC was $\left(18.2^{109} \mathrm{~L}\right.$ ), mainly neutrophil. A 24 hours maternal blood culture grew gram-positive cocci in pairs and Veillonella species of anaerobic Gram-negative cocci. Maternal urine culture grew no organisms. Diagnosis of maternal chorioamnionitis was made, and intravenous antibiotics were initiated two days before delivery. At birth, the Baby's Apgar scores were 9 and 10 at the first and fifth minutes of age, and birth weight was 2.6 kilograms. The baby was admitted to a step-down unite for further evaluation. At one hour of age, the in-charge nurse observed a few blood spots in the stool, mild abdominal distention, tachypnea without increased work of breathing, and poor sucking. The abdominal examination revealed mild abdominal distension with mild erythema. The baby was jaundiced. The Baby's CBC was $\left(4.6^{109} / \mathrm{L}\right.$ with neutropenia< $\left.50 \%\right)$, CRP $(108)$, blood culture grew no organisms after 72 hours, and the CSF study was normal. The abdominal $x$-ray showed a dilated and thickened bowel wall with a soap bubble appearance (Figure 1). The diagnosis of NEC was made. The baby started on intravenous antibiotics and continued nil by mouth and transferred to the NICU. Shortly after, the abdominal wall was getting more erythematous and spreading to the flanks, abdomen more distended, tender, and firm inconsis- tency. Repeated abdominal x-ray after 8 hours (Figure 2) showed pneumatosis intestinalis (PI). At 24 hours of age, abdominal ultrasound showed mild ascites with dilated bowel loops, thickened bowel wall, and normal arterial blood supply with PI (Figure 3). By the fourth day of life, the baby's clinical condition was improving. The baby continued antibiotics for 14 days though feeding started at 14 days of age. On day 20 of age baby was on full feed and clinically stable. Before discharge, a routine repeat of abdominal

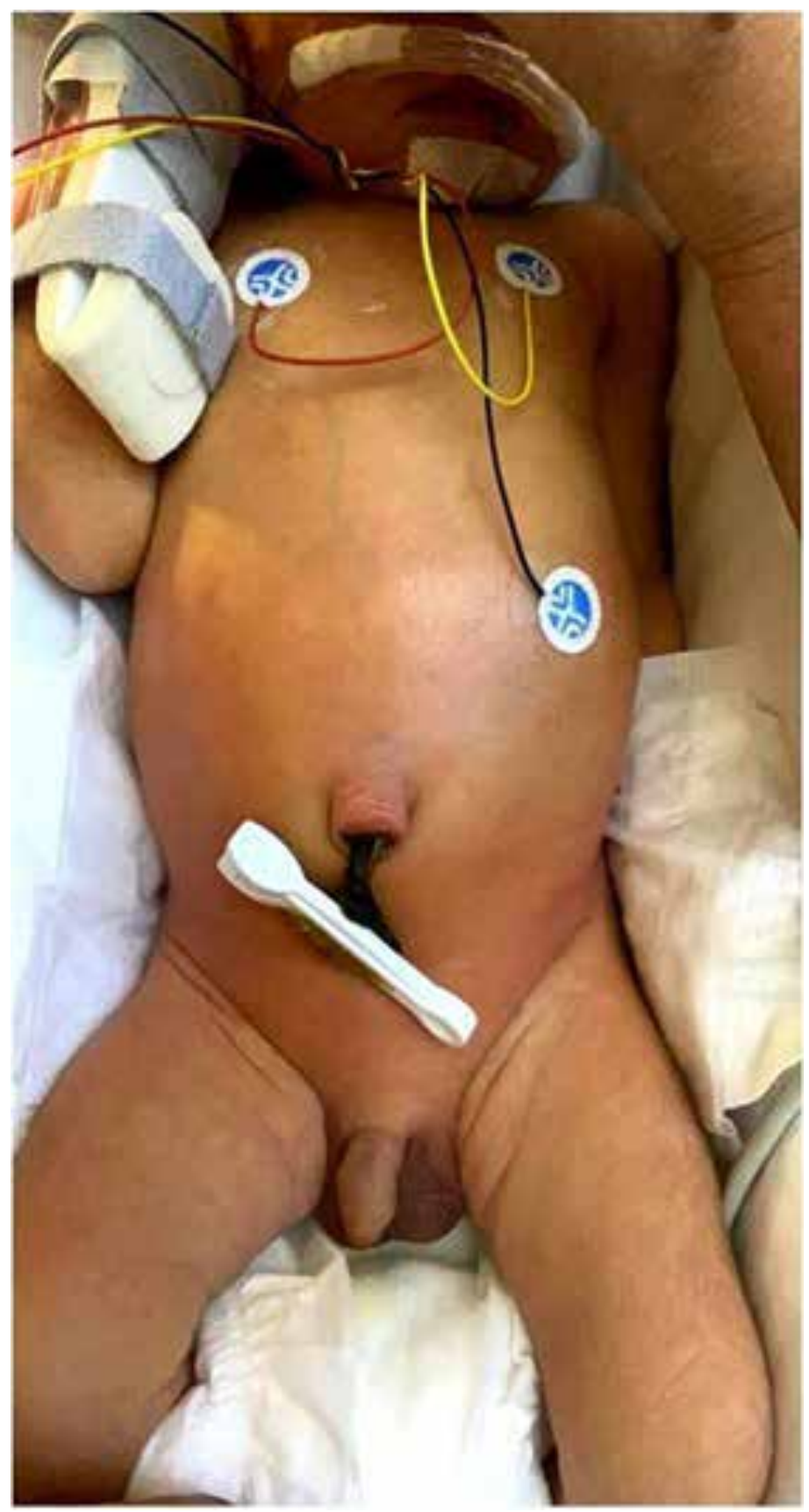

Figure 1b: Baby's abdomen at one hour of age, note the distension and bowel wall erythema 


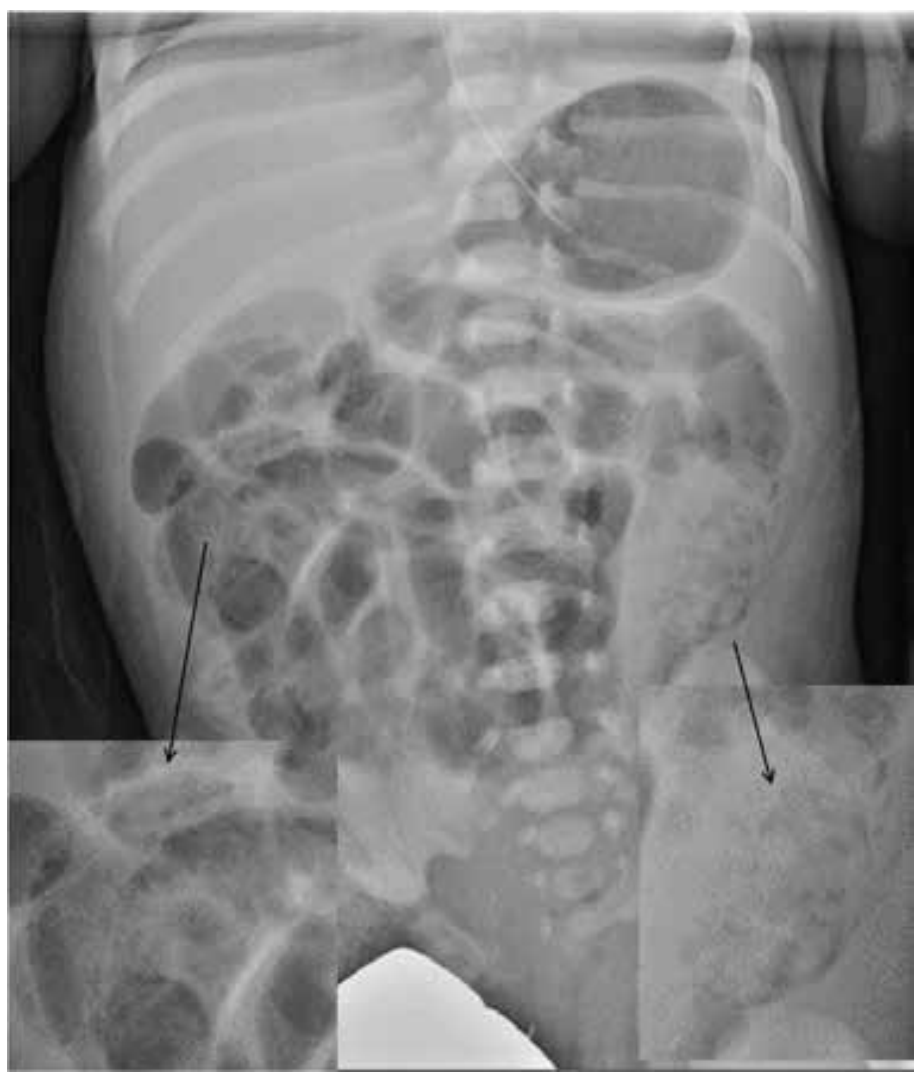

Figure 1a (one hour of age): Plane abdominal x-ray: note bubble soap appearance in the right upper and lower left quadrant.

x-ray (figure 3) showed significant bowel wall dilatation with significant stool retention. Contrast enema (figure 4) revealed a stricture of the proximal part of the rectum; the baby underwent successful surgical colostomy and was discharged home at 2 months of age.

\section{Discussion:}

Necrotizing enterocolitis is rare in full-term newborns. The main risk factors for NEC in FTN are listed in table 1. All will share one basic pathogenesis: mesenteric hypoxia and ischemia leading to intestinal mucosal necrosis. These risk factors should be allied with the early and fast introduction of milk. Rarely FTN will develop NEC before commencing the first feed; otherwise, as in this baby. This baby has established two maternal risk factors, chorioamnionitis, and antiphospholipid syndrome. Antiphospholipid syndrome is an acquired thrombophilia that causes blood clots and thrombi to form in the placenta. It is a recognized cause for recurrent abortion, stillbirth, IUGR, gestational hypertensive disorders, Fetal and neonatal thrombosis. More than $60 \%$ of newborns with aPL-related perinatal thrombosis had at least one additional risk factor identified, such as arterial and venous catheters, sepsis, asphyxia, and inherited thrombophilia. (1)

During the perinatal period, aPL may be present in $30 \%$ of newborns of affected mothers. Perinatal thrombosis and other aPL-related clinical manifestations are rare, while NEC is never reported as a complication. (2) In this case report, the $\mathrm{x}$-ray was suggestive of soap bubble appearance and circular PI in the first $\mathrm{x}$-ray while it became linear $\mathrm{PI}$ in the second $\mathrm{x}$-ray with thickened and dilated bowel wall (Figures 1 \&2). The presence of pneumatosis

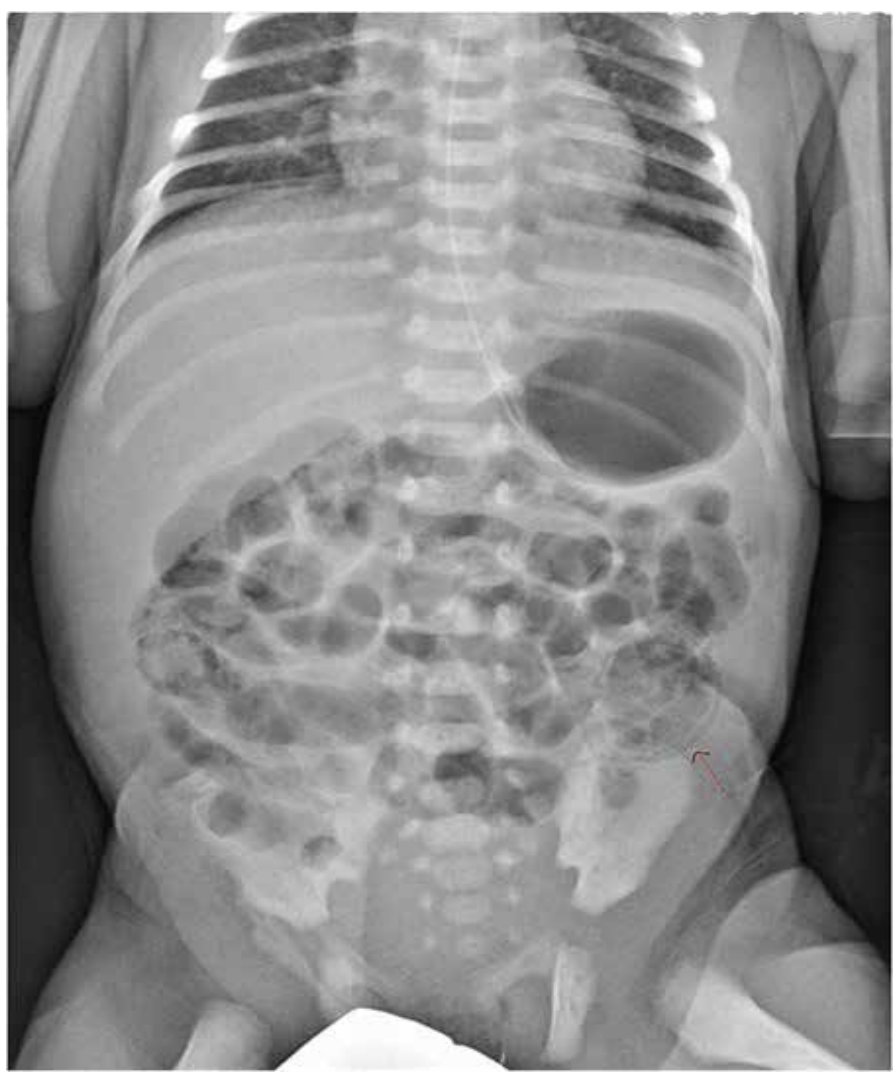

Figure 2a: Plane abdominal x-ray ( 8 hours of age): note linear and circular $P I$ in the right upper and lower left quadrant.

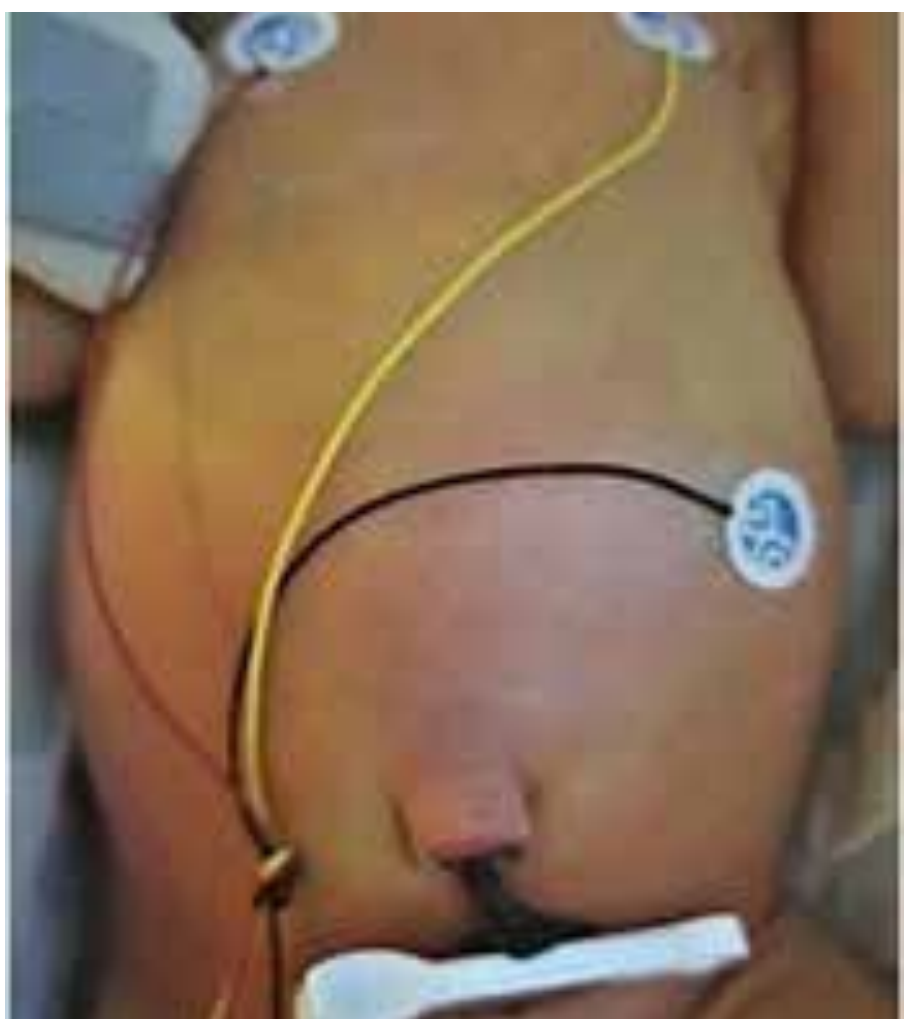

Figure 2b: Baby's abdomen, more distension, and more bowel wall erythema 


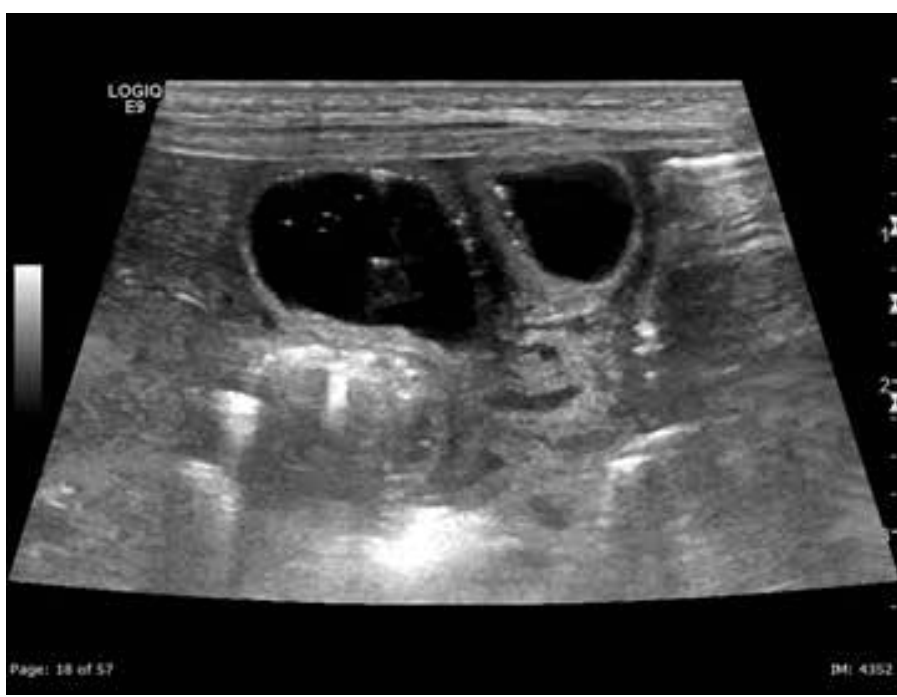

Figure 3 Ultrasound at 24 hours of age: gas shadows within the mural wall. Dilated loops filled with fluid at left lower abdomen \& free intraperitoneal fluid in between the bowel

intestinalis in both $x$-rays should support the diagnosis of NEC. Subsequent $\mathrm{x}$-ray series showed no PI but a more thickened dilated bowel wall. According to Modified Bell's criteria of NEC, this case fits in stage $2 B$. (3)

\section{Maternal Risk Factors:}

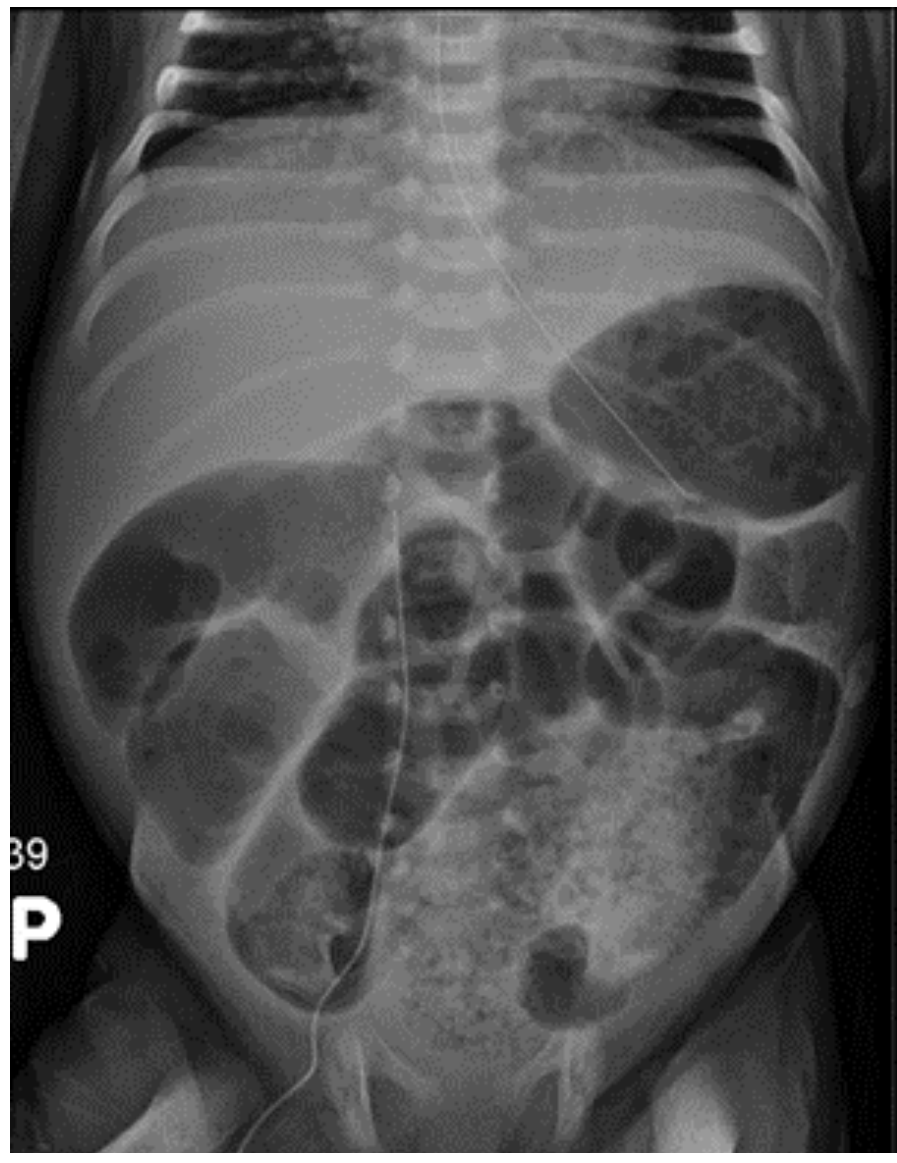

Figure $4 a$ at 20 days of age: severe bowel wall distension
Maternal conditions that stimulate the fetal intestinal inflammatory cascade, such as pregnancy-induced hypertension, maternal infection, issues with placental blood flow, or recreational drug use (cocaine) with injury to the vasculature in the watershed areas may trigger mucosal damage process and NEC.(4-6). Histological chorioamnionitis and associated vasculitis increase the risk of an infant developing NEC 2.5-fold (odds ratio [OR] 2.6, $P=0.02$ ). (7)

\section{Intrapartum risk factors:}

The major intrapartum risk factor is a hypoxic-ischemic insult to the fetus. (8) Though unlikely a major cause of NEC in the very preterm infant, hypoxia and ischemia modulate microvascular tone and vascular regulators such as endothelin and epidermal growth factor that play a role in the development of NEC. (9)

\section{Incidence:}

In a case-control study of 43 FTN who developed NEC, Wiswell et al. demonstrated that NEC in FTN accounted for $12 \%$ of NEC cases diagnosed in his center. At the onset, the median age was two days, and 18 infants developed NEC on the first day of life. Two $(4.7 \%)$ of the 43 affected infants died. Only three of the full-term infants who subsequently developed NEC had entirely unremarkable courses before the onset of symptoms. Sick infants, those who are small for gestational age or require exchange transfusions, are at risk for NEC. The mortality rate in FTN is significantly less than those figures reported in the preterm age group. (11-15)

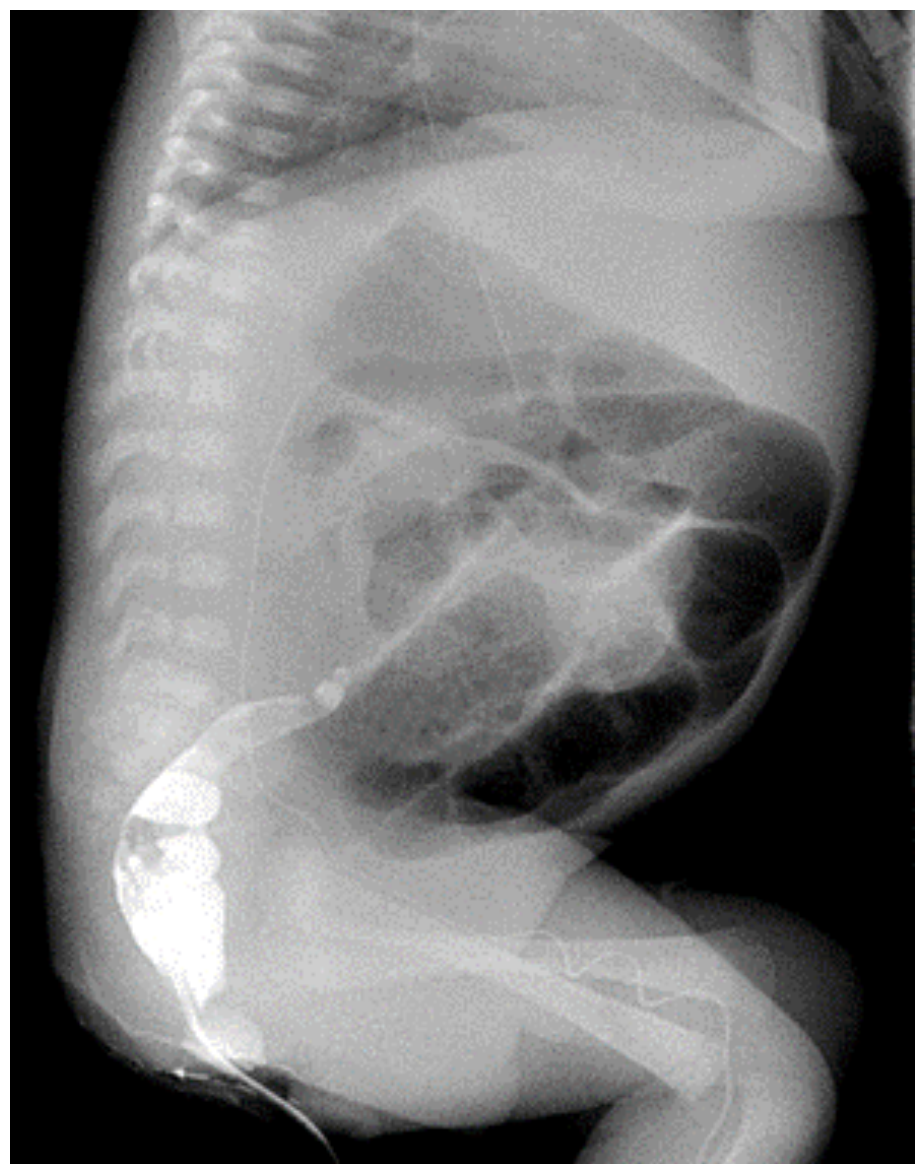

Figure 4b: Contrast study: note sigmoid colon stricture 
In another case-control study, the incidence reported was as 0.16 to 0.71 per 1000 live births. (16) In China, NEC in FTN was reported as low as $0.44 \%$, of which $20 \%$ were LBW. (17)

\section{Diagnosis:}

Radiology is considered the gold standard tool for the diagnosis of NEC. Often, infants with NEC do not have specific radiological findings. Frequently infants with NEC or those developing NEC manifest nonspecific metabolic or respiratory acidosis, thrombocytopenia, and neutropenia. The blood culture is positive in less than a third. $(18,19)$ Some authors will distinguish FTN NEC from the true NEC seen in very preterm $<32$ weeks gestation infants and occurring during the second or third week of life. (21)

\section{"Pl is often detected by plain films of the abdomen early, which will be positive in approximately two-thirds of $x$-ray films, and its presence will last a short period then be replaced by a more thickened bowel wall as air is already absorbed."}

Against this perspective, NEC is a state of pathology with clear criteria that do not include the newborn's gestation age. The hallmark of diagnosing NEC lies not only within the clinical condition but also within the radiological findings. Those are pneumatosis intestinalis, gas in the portal venous track of the liver, or the more serious pneumoperitoneum.

$\mathrm{PI}$ is often detected by plain films of the abdomen early, which will be positive in approximately two-thirds of x-ray films, and its presence will last a short period then be replaced by a more thickened bowel wall as air is already absorbed. Intramural gas tracks along the bowel wall can be either linear, which are usually submucosal, or rounded cystic "bubbly" collections, which are usually subserosal. Where they join, they may outline the circumferential margin of the bowel, creating rings (this circular pattern of $\mathrm{PI}$ favors a benign pathology, whereas the linear and bubbly lucencies can be associated with any, i.e., either benign or life-threatening causes). Radiological findings of ileus or thickened, dilated, and fixed loop are nonspecific, but a finding of intraluminal $(P I)$ or portal gas, which is present in $50-75 \%$ of cases, are considered diagnostic. Shebrya et al. have shown that abdominal ultrasound is more sensitive than plain X-ray abdomen. (Figure 4). To date, serial KUB and cross-table lateral are the most often used studies to detect the subtle collection of free air in the abdomen. (22-26)

Table 1: risk factors of NEC in full-term infants.

1. Hypoxic-ischemic encephalopathy with early feeding

2. Placental insufficiency led to reversed diastolic

3. Maternal substance abuse (cocaine)

4. Maternal chorioamnionitis

5. Maternal hypertension.

6. Blood transfusion using old stored blood.

7. Exchange transfusion

8. Sepsis

9. IUGR
10. Severe anemia

11. Gastroschisis, diaphragmatic hernia, and Hirschsprung disease

12. Polycythemia with hyperviscosity

13. Prolonged infusion of prostaglandin infusion

\section{References:}

1. Claudia Saad Magalhães, MD, ${ }^{*}$ Ligia Maria Suppo de Souza Rugolo, MD,† Cleide Enoir Petean Trindade, MD. Neonatal Antiphospholipid Syndrome. NeoReviews Vol.15 No.5 May 2014 e169.

2. Avcin T. Antiphospholipid syndrome in children. Curr Opin Rheumatol. 2008;20(5):595-600

3. Neonatal necrotizing enterocolitis. Therapeutic decisions based upon clinical staging. Bell MJ, Ternberg JL, Feigin RD, Keating JP, Marshall R, Barton L, Brotherton T. Ann Surg. 1978 Jan; 187(1):1-7.

4. Neish AS. Molecular aspects of intestinal epithelial cell-bacterial interactions that determine the development of intestinal inflammation. Inflamm Bowel Dis 2004;10:159-68.

5. Hand IL, Noble L, McVeigh TJ, Kim M, Yoon JJ. The effects of intrauterine cocaine exposure on the respiratory status of the very low birth weight infant. J Perinatol 2001;21:372-5.

6. Bashiri A, Zmora E, Sheiner E, Hershkovitz R, Shoham-Vardi I, Mazor M. Maternal hypertensive disorders are an independent risk factor for the development of necrotizing enterocolitis in very low birth weight infants. Fetal Diagn Ther 2003;18:4047.

7. Ogunyemi $D$, Murillo $M$, Jackson $U$, Hunter $N$, Alperson $B$. The relationship between placental histopathology findings and perinatal outcome in preterm infants. J Matern Fetal Neonatal Med 2003;13:102-9

8. Desfrere L, de Oliveira I, Goffinet F, El Ayoubi M, Firtion G, Bavoux $F$, et al. Increased incidence of necrotizing enterocolitis in premature infants born to HIV-positive mothers. AIDS 2005;19:1487-93.

9. Nowicki PT, Nankervis CA. The role of the circulation in the pathogenesis of necrotizing enterocolitis. Clin Perinatol 1994;21:219-34

10. Warner BB, Ryan AL, Seeger K, Leonard AC, Erwin CR, Warner BW. Otogeny of salivery epidermal growth factor and necrotizing enterocolitis. J Pediatr 2007;150:358-60.

11. (Ahle M, Drott $P$, Andersson RE. Epidemiology and trends of necrotizing enterocolitis in Sweden: 1987-2009. Pediatrics 2013;132:e443-51)

12. Wiswell TE, Robertson CF, Jones TA, Tuttle DJ. Necrotizing Enterocolitis in Full-term Infants: A Case-Control Study. Am J Dis Child. 1988;142(5):532-535. doi:10.1001/archpedi.1988.

13. Fitzgibbons SC, Ching Y, Yu D, Carpenter J, Kenny M, Weldon $C$, et al. Mortality of necrotizing enterocolitis expressed by birth weight categories. J Pediatr Surg 2009;44:1072-5.

14. Neu J, Walker WA. Necrotizing enterocolitis. N Engl J Med 2011;364:255-64.

15. Hintz SR, Kendrick DE, Stoll BJ, Vohr BR, Fanaroff AA, Donovan EF, et al. Neurodevelopmental and growth outcomes of extremely low birth weight infants after necrotizing enterocolitis. Pediatrics 2005;115:696-703.

16. Bedrick $A D$. Necrotizing enterocolitis: Neurodevelopmental "risky business". J Perinatol 2004;24:531-3.

17. Maayan-Metzger A, Itzchak A, Mazkereth R, Kuint J. Necrotizing enterocolitis in full-term infants: case-control study 
and review of the literature. J Perinatol. 2004;24(8):494-499. doi:10.1038/sj.jp.7211135

18. Qian T, Zhang $R$, Zhu L, et al. Zhonghua Yi Xue Za Zhi. 2016:96(22):1766-1772. doi:10.3760/cma.j.is sn.0376-2491.2016.22.012

19. Gregory KE, Deforge CE, Natale KM, Phillips M, Van Marter LJ. Necrotizing enterocolitis in the premature infant: Neonatal nursing assessment, disease pathogenesis, and clinical presentation. Adv Neonatal Care 2011;11:155-64

20. Sharma R, Garrison RD, Tepas JJ 3 rd, Mollitt DL, Pieper P, Hudak ML, et al. Rotavirus-associated necrotizing enterocolitis: An insight into a potentially preventable disease? J Pediatr Surg 2004;39:453-7

21. Haque KN. Necrotizing enterocolitis - Some things old and some things new: A comprehensive review. J Clin Neonatol ;2020 Aug 30;5:79-90.

22. Jayakumar S, Patwardhan N. Characteristic radiological findings in preterm infants with missed intestinal perforation. $J$ Neonatal Surg 2014;3:27

23. Mehta SN, Friedman G, Fried GM, Mayrand S. Pneumatosis cystoides intestinalis: laparoscopic features. Am J Gastroenterol. 1996;91(12):2610-2612

24. Jamart J. Pneumatosis cystoides intestinalis. A statistical study of 919 cases. Acta Hepatogastroenterol (Stuttg). 1979;26(5):419-422.

25. Kamali K, Hosseini SR, Ardakani SM, Farnoodi MR. Complementary value of sonography in early evaluation of necrotizing enterocolitis. Pol J Radiol 2015;80:317-23.

26. Shebrya NH, Amin SK, El-Shinnawy MA, Imam SS. Abdominal ultrasonography in preterm necrotizing enterocolitis. Is it superior to plain radiography? September 2012 Egyptian Journal of Radiology and Nuclear Medicine 43(3):457-463 DOI: 10.1016/j.ejrnm.2012.06.001

Disclosure: The authors have no disclosures.

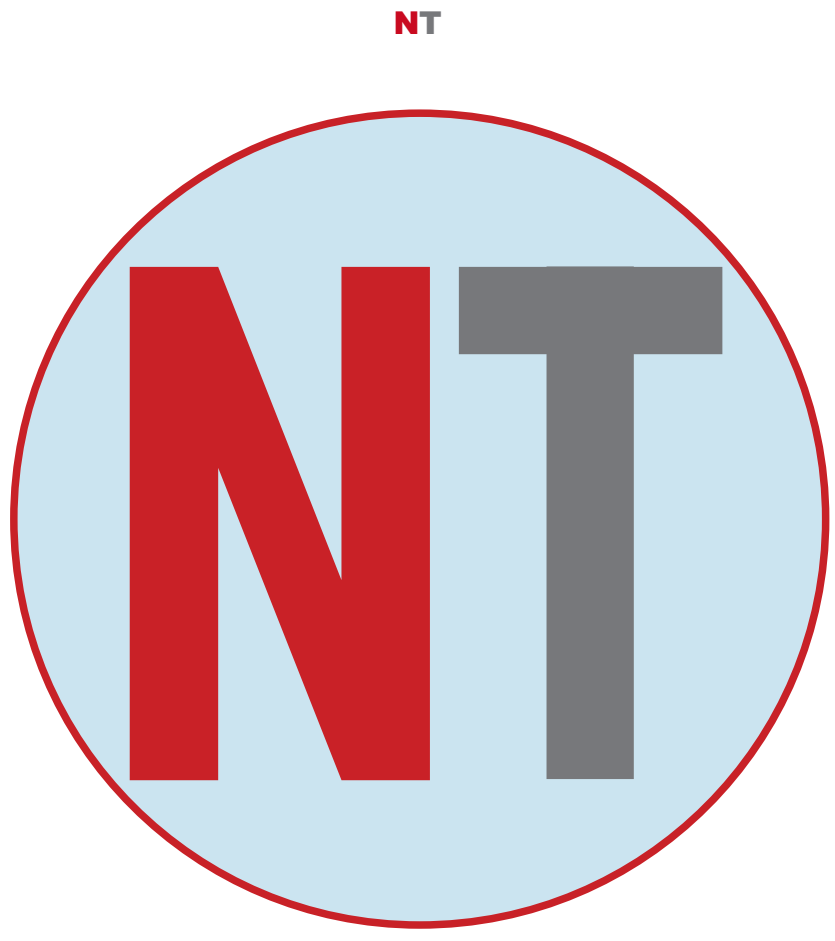

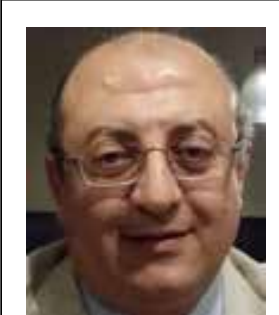

Corresponding Author

Husam Salama, MRCP (UK), DCCH (UK). DCH.

Senior Consultant Neonatology Women's wellness and research center hospital

Head NICU Research committee

Hamad Medical Corporation-

Doha Qatar

Telephone: 0974-55262159

husam salama < hus3038@yahoo.com>
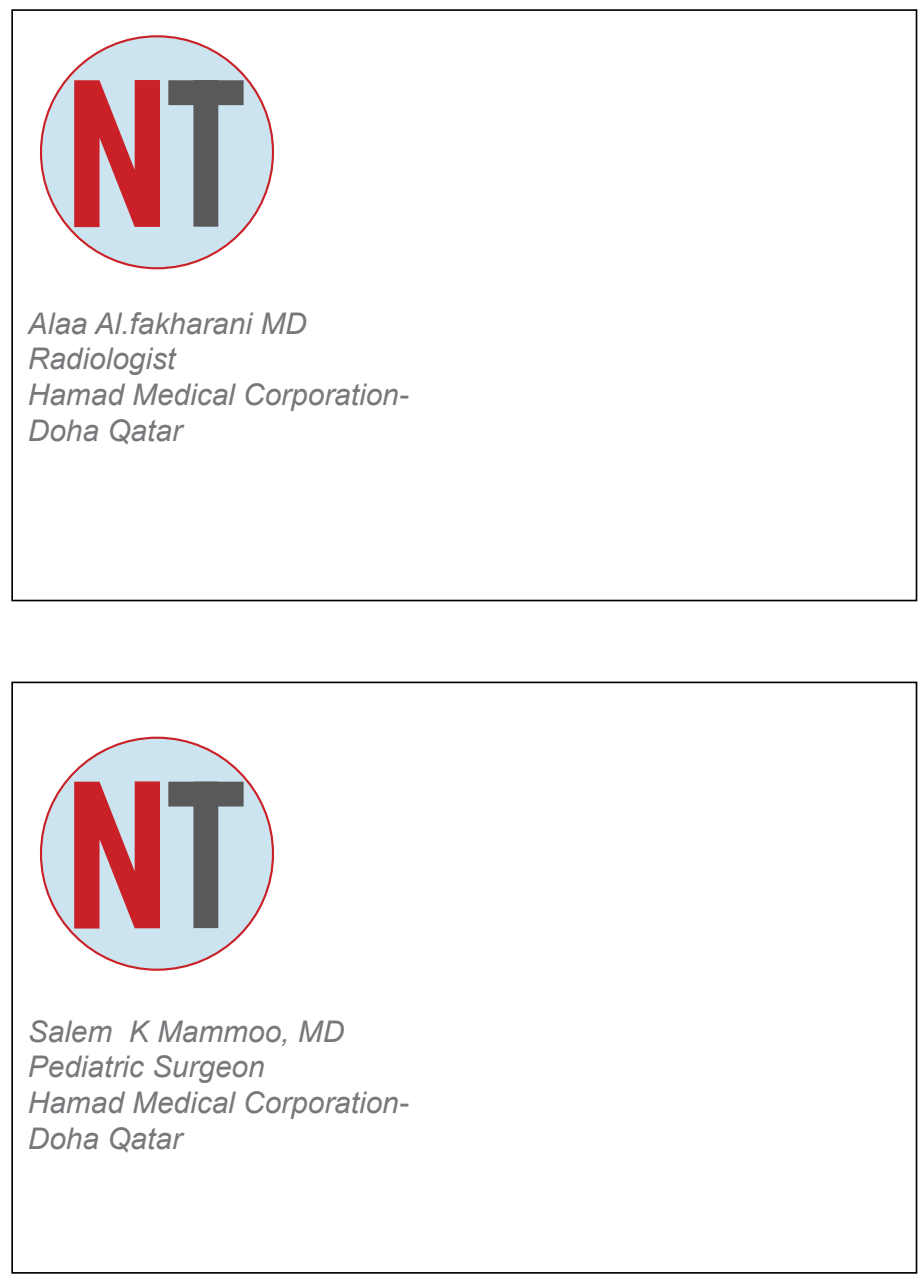